\title{
Diagnostyka płyt warstwowych za pomocą metody radarowej
}

\section{Diagnostics sandwich panels by gpr method}

\section{Streszczenie}

W pracy przedstawiono zastosowanie metody radarowej do oceny stanu technicznego i jakości wykonania ściennych płyt warstwowych. Przedmiotem badań były prefabrykowane płyty warstwowe zastosowane $w$ konstrukcji zewnętrznych ścian nośnych budynków wykonanych z płyt prefabrykowanych systemu W-70 w latach 70-tych ubiegłego wieku. Badaniom poddano także również płyty warstwowe wykonane w zakładzie prefabrykacji obecnie. Ocena stanu technicznego obejmowała określenie grubości poszczególnych warstw płyt, ilości i rozstawu zbrojenia oraz sprawdzenia istnienia ewentualnych nieciągłości i rozwarstwień warstw. Sprawdzenia poprawności i dokładności odczytów radarowych dokonano poprzez porównanie z wykonanymi odkrywkami w płytach systemu W-70 wbudowanych w konstrukcje, oraz z rysunkami warsztatowymi. Podano procedurę prowadzenia badań radarowych wraz z zaleceniami dotyczącymi ustawień aparatury badawczej. Podano wnioski i zalecenia wynikające $z$ analizy danych radarowych bazując na badaniach własnych i przeglądzie literaturowym. Wyniki badań posłużyły do określenia efektywności metody radarowej stosowanej do oceny stanu technicznego płyt warstwowych w budynkach „z wielkiej płyty".

Słowa kluczowe: metoda radarowa; płyty warstwowe; GPR; diagnostyka; system $\mathrm{W}-70$

\section{Abstract}

The paper presents the application of georadar method for sandwich panel assessment. The subject of research were precast sandwich panels comprising external supporting walls of a building designed in accordance to W-70 prefabrication system. Panels made in prefabrication plant were also investigated directly after its construction. The research concerned determination of panel layers' thickness, quantity and distance between rebar and verification of layers' delamination. The construction members of $\mathrm{W}-70$ system were verified by open pits and elements examined in the prefabrication plant by detail design. Application of filtering procedures was described and interpretation of the obtained results was discussed. Conducted research allowed to determine the efficiency of georadar method for precast sandwich panels' testing.

Keywords: radar method; sandwich panels; GPR; diagnostic; system W-70

\section{Wstęp}

Budynki z prefabrykatów są integralnym krajobrazem polskich miast. W większości były one wykonywane w technologii tzw. wielkiej płyty, a ich okres bezpiecznej pracy określany był na 50 lat. W trakcie ich użytkowania wprowadzano różnego rodzaju rozwiązania racjonalizatorskie (zmniejszano grubość ocieplenia, stosowano zbrojenie o innych średnicach i gatunku stali, zmniejszano liczbę szpilek i wieszaków) co prowadziło do powstawania różnego typu uszkodzeń (rozwarstwień, przemarzania, korozji zbrojenia). W międzyczasie zmieniały się także normy dotyczące izolacyjności ścian co dodatkowo zwiększało problemy związane z budynkami z tzw. wielkiej płyty [1]. Dlatego też w przypadku już istniejących budynków wybudowanych z płyt warstwowych, jak i nowo produkowanych elementach tak istotna jest diagnostyka oraz kontrola ich produkcji [16].
Przeprowadzono liczne badania nieniszczące związane $z$ diagnostyką podobnych elementów [17,18]. Jedną z możliwych metod badawczych jest technika radarowa, która umożliwia ocenę stanu technicznego oraz poprawność wykonania płyt warstwowych.

\section{Metoda radarowa}

Metoda radarowa jest to mobilna, geofizyczna metoda diagnostyczna, opierająca się na zjawisku odbicia fali elektromagnetycznej od granicy ośrodków, pomiędzy którymi występuje kontrast właściwości elektrycznych. Urządzeniem, który wykorzystuje tą metodę to georadar. Przed wykonaniem pomiaru należy dokonać odpowiedniej kalibracji

Dr hab. inż. Grzegorz Świt, prof. PŚk; mgr inż. Łukasz Sławski; mgr inż. Łukasz Kosno - Politechnika Świętokrzyska. Autor korespondencyjny/Corresponding author: lukaslaw@poczta.fm 
sprzętu. Kalibracja dotyczy określenia:

- długości okna czasowego i ilości próbek w śladzie,

- liczby złożeń (sumowania) sygnału,

- trybu i interwału zapisu śladów radarowych,

- częstotliwość próbkowania sygnału.

Zalecenia odnośnie poprawnego ustalenia tych parametrów można znaleźć w pracach [2] i [3]. Otrzymane dane w postaci obrazów falowych zwanych radargramami należy odpowiednio przetworzyć poprzez specjalistyczne oprogramowanie stosując odpowiednie procedury filtracyjne. Wybór procedur oraz ich kolejność jest bardzo istotna i jest związana bezpośrednio z celem badań. Tak przetworzone profile można poddać interpretacji. Przedstawione $\mathrm{w}$ artykule badania nieniszczące wykonane z zastosowaniem georadaru miały na celu odpowiednią diagnostykę trójwarstwowych elementów ściennych. Pomiary przeprowadzono przy użyciu georadaru impulsowego typu RIS-K2 Alladin oraz anteny bipolarnej o częstotliwości $2 \mathrm{GHz}$. Zastosowano próbkowanie sygnału o wartości 1024, natomiast akwizycję prowadzono w oknie czasowym o długości 20 ns. Pomiary na płycie wykonano w stałych interwałach odległościowych, równoległych względem siebie.

\section{Rezultaty badań}

Metoda radarowa pozwala na wgląd do wnętrza badanych prefabrykatów, co umożliwiło identyfikację elementów i warstw konstrukcyjnych. Przeprowadzono analizę profili radarowych, a otrzymane wyniki porównano z dokumentacją techniczną. Poniżej zaprezentowano interpretację jednego z nich przy zastosowaniu procedur filtracyjnych w wymienionej kolejności w oparciu o prace [4,5]:

- move start time - filtr przesuwa skan do poziomu zero,
- filtr wzmacniający liniowy - wzmacnia sygnał wg charakterystyki liniowej,

- odjęcie średniej ruchomej - usuwa zakłócenia o niskich częstotliwościach,

- pionowy filtr przepustowy - filtr częstotliwościowy o zakresie 1,7-2,0 GHz.

Poniższy profil przedstawia przekrój przez płytę ścienną systemu W-70. Widoczne są granice ośrodków beton-styropian, styropian-beton i beton-powietrze. Ich krzywoliniowy charakter wynika z lokalnych zmian prędkości propagacji fali EM w ośrodku. Zróżnicowanie prędkości propagacji fali w warstwach betonu i izolacji powoduje również, iż proporcje grubości warstw widoczne na profilu nie pokrywają się z proporcjami rzeczywistymi. Wierzchołki widocznych na górze radargramu paraboli pokrywają się z lokalizacją prętów zbrojenia warstwy fakturowej, poprzecznych do kierunku skanowania. Widoczna jest również szpilka stalowa występująca po lewej stronie skanu, wieszak na jego środku oraz kolejna szpilka po stronie prawej.

Na tej podstawie oraz w oparciu o literaturę określono najważniejsze wytyczne dotyczące diagnostyki elementów ściennych trójwarstwowych.

\section{Grubość warstw}

Przeprowadzono wiele badań oraz napisano liczne prace naukowe dotyczące określania grubości warstw elemen-

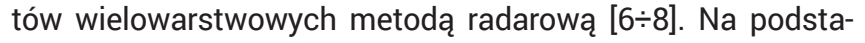
wie przeglądu literatury oraz badań własnych stwierdzono, że najważniejsze jest określenie prędkości rozchodzącego się sygnału w danej warstwie oraz czasu jaki potrzebował sygnał aby, przebyć daną warstwę. Czas możemy odczytać bezpośrednio z radargramu. Jednakże są aspekty na które należy zwrócić szczególną uwagę przy odczycie. Bardzo istotne jest
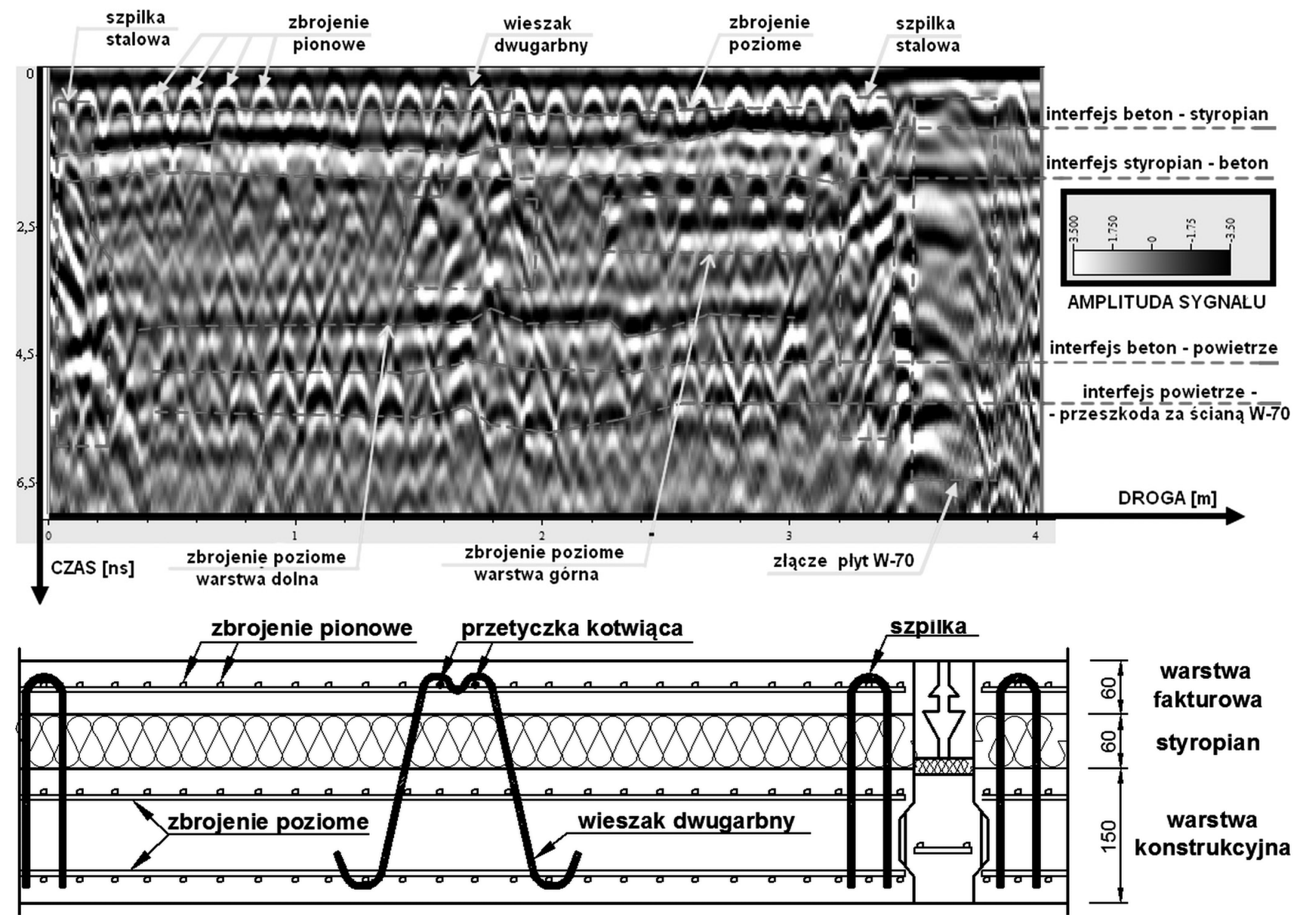

Rys. 1. Profil georadarowy płyty ściennej wraz z interpretacją

Fig. 1. Wall panel georadar profile and its interpretation 
aby na radargramie dokładnie wychwycić granicę ośrodków. Poniżej zaprezentowano dwa przypadki profili radarowych uzyskanych za pomocą jednego skanu i zaznaczono na nich granice ośrodków (Jest to możliwe wyłącznie przy wykorzystaniu anteny bipolarnej gdyż posiada dwie pary anten spolaryzowanych prostopadle). Pierwszy z nich dotyczy anten ułożonych równolegle do siebie, przesuwających się prostopadle do wytyczonego profilu pomiarowego. W takim usytuowaniu pole elektryczne jest spolaryzowane równolegle do dłuższej osi anteny. Natomiast w drugim anteny również były ułożone równolegle do siebie lecz przesuwały się równolegle do wytyczonego profilu pomiarowego przez co pole elektryczne jest spolaryzowane prostopadle do dłuższej osi anteny. Łatwo zauważyć, że cele zlokalizowane prostopadle do kierunku ruchu anteny (równoległe do dipoli anteny) wykazują największą wrażliwość tzn. duża część energii sygnału od nich jest odbijana, przez co są łatwe do wychwycenia. Liczność odbić w takim przypadku może zakłócać poprawną interpretację granic ośrodków, wtedy możemy się posłużyć radargramem, gdzie dipole są zorientowane prostopadle do kierunku ruchu anteny. Tak jest w podpunkcie B rysunku 2, gdzie odbicia prostopadłe do kierunku ruchu anteny nie zostały wychwycone.

Poprawna interpretacja granicy ośrodków, pozwala na odczyt czasu w jakim nastąpiło przejście z jednego ośrodka w drugi posługując się pojedynczym rozkładem amplitudy sygnału co przedstawia rysunek 3 .
Tam gdzie sygnał zaczyna zmieniać gwałtownie swoją prędkość z mniejszej na większą towarzyszy temu zmiana amplitudy sygnału $z$ ujemnego na dodatni i analogicznie w przeciwnym przypadku.

Drugim ważnym czynnikiem przy określaniu grubości warstw tak jak wspomniano jest prędkość rozchodzenia się impulsu. Sposoby jego określania stanowi :

- tablica fizyczna (Jeżeli znamy materiał z którego wykonano daną warstwę),

- kształt hiperboli (Bezpośrednio odczytując z programu (Jest to możliwe gdy badana warstwa zawiera obiekt zlokalizowany prostopadle do linii skanowania)),

- amplituda sygnału (Patrz praca [9]).

Jednakże należy też pamiętać o tym, że w przypadku gdy dany ośrodek jest zawilgocony lub mocno niejednorodny, metoda ta staje się bardzo nieefektywna, gdyż prędkość impulsu rozchodzi się w takim ośrodku w bardzo zróżnicowany sposób. Również w przypadku granicy ośrodków o podobnych właściwościach dielektrycznych może być ona trudna do wykrycia. O dokładności wyników stanowi rozdzielczość pozioma i pionowa, którą szczegółowo opisano w pracy [2]. Istnieją również modele obliczeniowe za pomocą których określa się grubości warstw w zależności od stopnia wilgotności elementu [10], jednakże złożoność ich zastosowania nie nadaje się obecnie do praktycznego zastosowania.

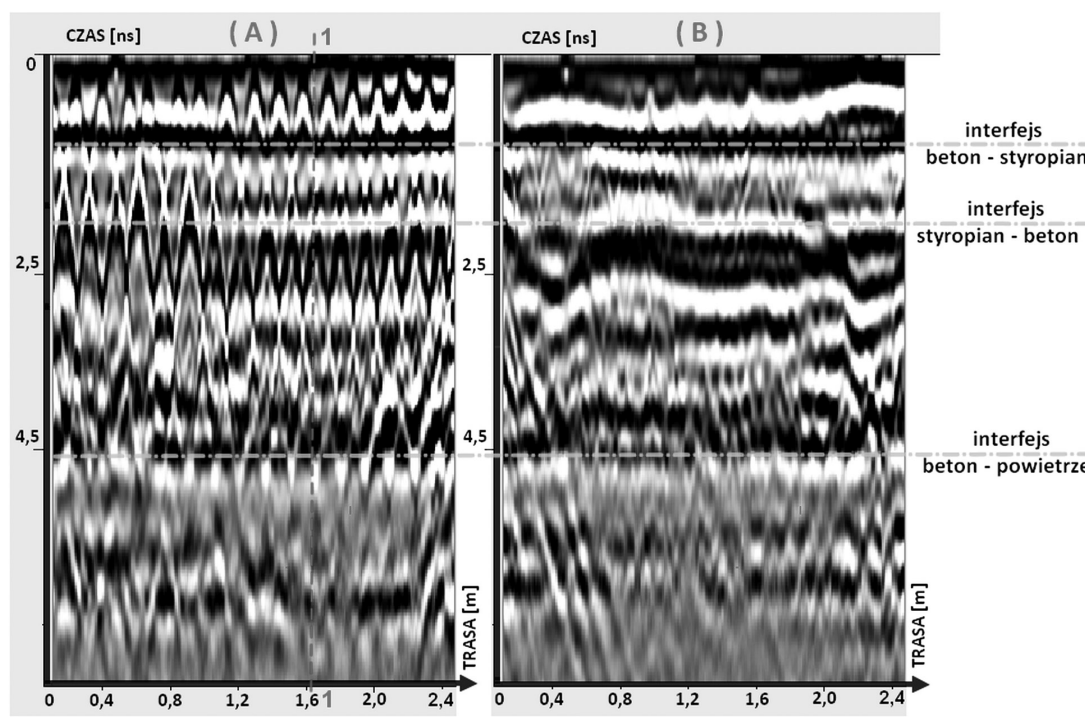

Rys. 2. Profil georadarowy płyty ściennej wraz z zaznaczeniem granic ośrodków Fig. 2. Wall panel georadar profile with marked interface
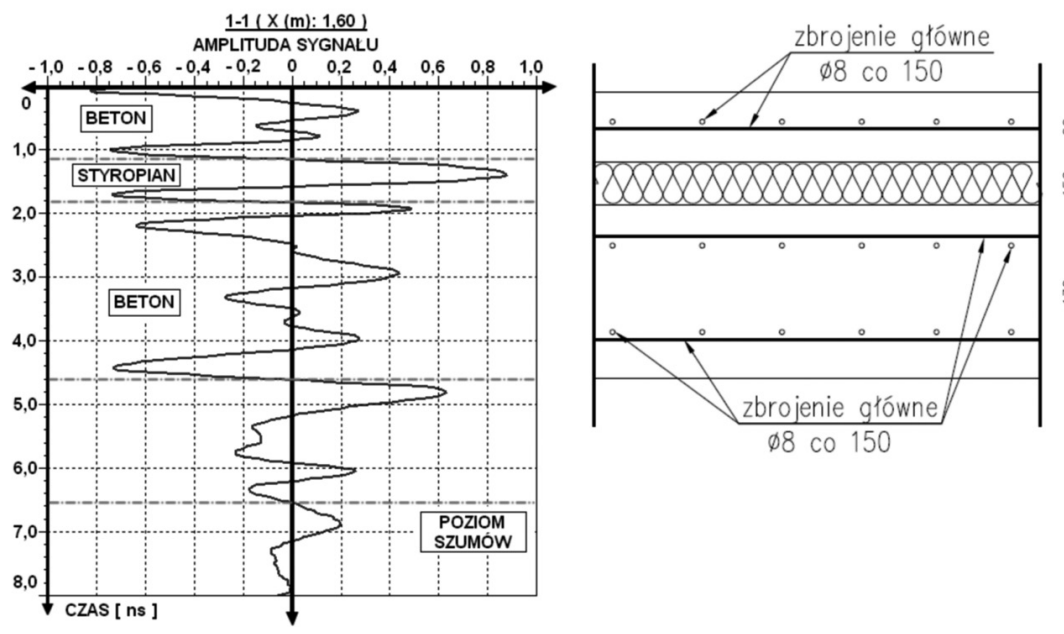

Rys. 3. Pojedynczy ślad radarowy w przekroju 1-1 i jego interpretacja Fig. 3. Single georadar trace in cross section 1-1 and its interpretation

\section{Ilość i rozstaw zbrojenia}

Bardzo wiele elementów warstwowych ściennych stanowią płyty betonowe. Zbrojenie w nich zawarte stanowi najczęściej siatka prętów ułożonych prostopadle względem siebie. Za pomocą metody radarowej można określić rozstaw tych prętów oraz ich położenie. Natomiast oszacowanie za pomocą georadaru średnicy pręta jest bardzo nieefektywne ze względu na poziom dokładności $\pm 5 \mathrm{~mm}$, jednakże obecnie podejmowane są próby numeryczne przetwarzania danych radarowych, które pozwalają na uzyskanie znacznie większej precyzji, ale są one dopiero wdrażane na świecie [11].

Radargramy jakie uzyskano dla płyt W-70 z otworem okiennym wykazały brak pionowych prętów zbrojenia warstwy fakturowej ponad otworem okiennym. Wierzchołki parabol obrazujące pręty poprzeczne do kierunku skanowania (pionowe) występują tylko z lewej i prawej strony (rys. 4).

Odległości między wierzchołkami parabol stanowi rozstaw zbrojenia pionowego w płycie. Metoda ta zezwala na szybki i prosty sposób kontroli zbrojenia, jednakże istnieją warunki kiedy jest nieefektywna. Przy detekcji drugiego rzędu zbrojenia i niższych, jak i zarówno prętów w nich zawartych należy zwrócić uwagę na:

- odległość między rzędami zbrojenia musi być w odległości większej niż 1/4 długości fali rozchodzącej się $\mathrm{w}$ betonie, aby na radargramie zobaczyć je oddzielnie,

- dwa pręty będące na tej samej głębokości przy odstępie bocznym mniejszym niż $5 \mathrm{~cm}$ na radargramie będą przedstawiane jako jeden obiekt, 


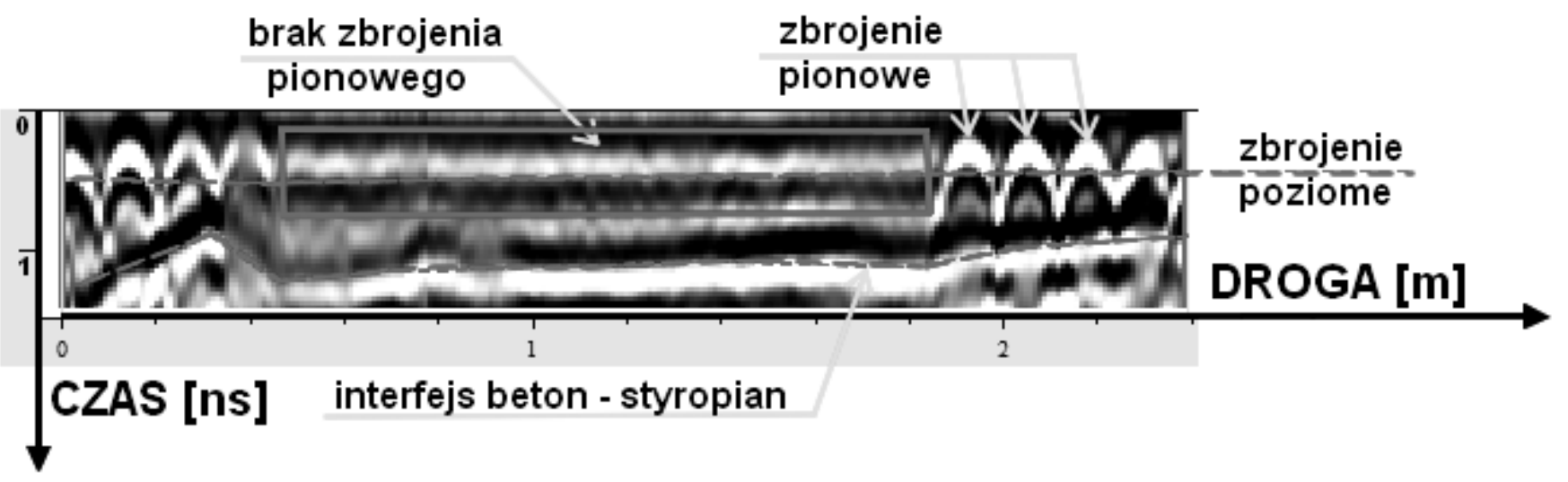

Rys. 4. Przekrój radarowy przedstawiający brak prętów zbrojeniowych nad otworem okiennym

Fig. 4. Radar cross-section presenting lack of rebar above the window opening

- sygnał radarowy przeniknie metalową siatkę zbrojenia, jeżeli rozstaw zbrojenia jest większy niż długość fali rozchodzącej się w betonie,

- stożek promieniowania anteny musi objąć badany rząd zbrojenia,

- głębiej usytuowany pręt tzn. w niższym rzędzie może być niewidoczny jeżeli znajduje się bezpośrednio pod innym prętem lub w bliskiej odległości.

Uwagi te wychwycono w oparciu o badania własne i prace naukowe $[12,13]$.

\section{Rozwarstwienie}

W przypadku badań własnych nie udało się zlokalizować delaminacji warstw, natomiast istniej wiele prac poświęconych temu zagadnieniu [14,15]. Niestety i w tym przypadku wady stosowania metody radarowej to:

- zakłócenia szumami, które mogą być błędnie interpretowane i traktowane jako rozwarstwienie,

- pojawienie się tzw. artefaktów, które przedstawiają zakłamany obraz rzeczywistości,

- dokładność metody zależna od rozdzielczości poziomej i pionowej.

\section{Podsumowanie}

Ocena stanu technicznego płyt warstwowych jest możliwa przy zastosowaniu metody radarowej. Jednakże aby móc w sposób efektywny z niej korzystać należy spełnić szereg kryteriów. Dotyczy to takich aspektów jak:

- odpowiednia kalibracja,

- poprawna filtracja danych radarowych,

- znajomość aspektów w przypadku, których metoda nie jest miarodajna.

Rozwój techniki w przeciągu kilku ostatnich lat spowodował, że niektóre ograniczenia metody są całkowicie lub częściowo zniwelowane. Jednakże są potrzebne dalsze badania w celu eliminacji kolejnych przeszkód.

\section{Literatura}

[1] M. Wójtowicz: Możliwość awarii warstwowych ścian zewnętrznych budynków wielkopłytowych - problem realny czy sensacja medialna, materiały konferencyjne, XXV Konferencja Naukowo-Techniczna, s. 533-542, 24-27.05.2011, Międzyzdroje.

[2] A. P. Annan: Introduction to GPR, Sensor \& Software, Inc. - Tutorial notes, 2003, Canada.

[3] A. P. Annan: Ground Penetrating Radar in Near-Surface Geophysics, in Investigations in Geophysics, No. 13 Society of Exploration Geophysicists, pp. 357-438, 2005.

[4] B. Rajchel: Analiza przydatności metody georadarowej do badania stropów budynków, Przegląd Geologiczny, vol.62, nr. 10/2, 2014.

[5] J. Karczewski: Zarys metody georadarowej, Uczelniane wydawnictwo naukowo - dydaktyczne AGH, 2007, Kraków.

[6] A. Giannopoulos, N. Diamanti: A numerical investigation into the accuracy of determining dielectric properties and thicknesses of pavement layers using reflection amplitude GPR data, 10-th International Conference on Ground Penetrating Radar, pp. 655-658, 21-24 June 2004, Delft, The Netherlands.

[7] A. Loizos, Ch. Plati: Accuracy of pavement thicknesses estimation using different ground penetrating radar analysis approaches, NDT\&E International, vol. 40, pp. 147-157, March 2007.

[8] K.R. Maser, T. Scullion, W.M.K. Roddis, E. Fernando: Radar for pavement thickness evaluation, Non - destructive testing of pavements and backcalculations of moduli: ASTM STP 1198, vol. 2, American Society of Testing Materials, pp. 343-360, 1994, Philadelphia, USA
[9] I. L. Al-Qadi, S. Lahouar: Measuring layer thicknesses with GPR - Theory to practice, Construction and Building Materials 19; pp. 763-772, 2005.

[10] T. Bourdi, F. Boone, J. E. Rhazi, G. Ballivy: Progress In Electromagnetic Research M., Vol. 28, pp. 89-99, 2013.

[11] Che Way Chang, Chen Hua Lin, Hung Sheng Lien: Measurement radius of reinforcing steel bar in concrete using digital image GPR, Construction and Building Materials 23, pp. 1057-1063, 2009.

[12] GSSI Handbook For RADAR Inspection of Concrete, Geophysical Survey System, August 2006, USA.

[13] Ł. Topczewski: Improvement and application of GPR Non - destructive Technique for the concrete bridge inspection, doctoral thesis, July 2007, Portugal.

[14] ASTM, Standard Test Method for Evaluating Asphalt - Covered Concrete Bridge Decks Using Ground Penetrating Radar Designation D 6087-08, ASTM International, 2005, West Conshohocken, Pennsylvania, USA.

[15] K. R. Maser. Integration of GPR and infraned thermography for bridge deck condition, NDTCE'09, 2009, France.

[16] R. Runkiewicz: Stosowanie metod nieniszczących do oceny stanu technicznego budynków wielkopłytowych, Przegląd Spawalnictwa, Vol. 86, nr 10, 2014, str. 51-59.

[17] K. Schabowicz: lokalizacja imperfekcji w płycie betonowej za pomocą tomografii ultradźwiękowej, Przegląd Spawalnictwa, Vol. 87, nr 12, 2015, str. 14-16.

[18] G. Świt, A. Krampikowska, K. Schabowicz: Zastosowanie metody emisji akustycznej do lokalizacji uszkodzeń w zbiorniku na produkty ropopochodne, Przegląd Spawalnictwa, Vol. 87, nr 12, 2015, str. 50-54. 